Article

\title{
Blog Use in K-12 Scottish Foreign Language Courses
}

\section{Modern Foreign Language Environment Supports Creative Uses of Technology}

\author{
Ewan McIntosh \\ National Adviser: Learning and Technology Futures \\ Learning and Teaching Scotland \\ The Optima, 58 Robertson Street, Glasgow, G2 8DU \\ Personal blog: \\ http://edu.blogs.com \\ Who's doing what in Scottish classrooms now?: \\ http://www.LTScotland.org.uk/connected
}

\section{Introduction}

With the support of the Learning and Teaching Scotland (LTS) organization, modern foreign language teachers in Scotland have begun integrating new technologies in their teaching practices. The LTS organization is a government-sponsored group that provides curriculum development and teacher support to teachers working with students at all pre-university levels of instruction, from 0-18 years of age. As a result of the efforts of the LTS over the last two years, teachers have increased their use of digital multimedia tools in the classroom. Teachers are taking advantage of quick and easy publishing of text, image, audio and video; they are creating class blogs, radio shows (or "podcasts") in the foreign language, revision guides, vocabulary help pages; they are also using mobile phones for language learning and undertaking their own professional development through these new technologies. The Modern Foreign Language Environment (MFLE) branch of the LTS provides subject-specific support for integrating new technologies into the foreign language curriculum. The MFLE emphasizes best practices in the use of new technologies and provides multiple means of support to help teachers understand how adopting technologies may require modifying teaching strategies and pedagogies. Indeed, national teacher training institutes have begun to use MFLE resources and materials to adapt their teaching training courses to include these emerging pedagogies.

This article concentrates one area of technical and pedagogical change in foreign language 
education, namely the use of weblogs, or "blogs." A blog is an Internet tool that can be used to publish easily text, images, audio or video without any in-depth knowledge of the Internet or complicated computer code. The ease of use of this Internet technology has resulted in its adoption by language instructors in various ways. This article will describe four different models of writing assignments developed by teachers with the support of the MFLE and will report student and teacher responses to using blogs in foreign language instruction. The four models of writing assignments include: 1) Group journal blog; 2) Best work blog; 3) School trip blog; and, 4) Webquest blog. These models provide a range of ownership and management possibilities for the writing space, from purely teacher-controlled space to collaborative student space. The writing in these activities is also undertaken in a variety of environments, from computer classroom, to library, to international field trip, to the student's home. Writing is also done collaboratively or individually and with the teacher as the primary audience or for a world-wide audience. Each of these factors influences the type of writing assignment and the pedagogical goal achieved and the students' responses to the writing activity.

The MFLE considers the adoption of online writing activities via blogs as a natural educational response to the growth in popularity of online social networking sites. Social networking sites such as MySpace, MSN Spaces, Bebo, and Facebook, are websites that offer users a means for writing and publishing their thoughts and ideas for others to read, a means of sharing photos and videos, and a way to create a virtual network of friends who may or may not be in close geographical proximity. These sites are familiar and popular among teenagers and increasingly being used by younger children, the "tweens," those in the few years towards the end of elementary school. In Ireland, for example, there are over one million users of the social networking site Bebo.com. This fact is especially remarkable when one keeps in mind that the total population of Ireland is four million. ${ }^{1}$ The flexibility and reach of the medium have made it a popular means for mainstream news media outlets to communicate with its audience and to engage new readers and listeners of a younger demographic. Mainstream news channels now often have blogs to accompany or supplement their regular news coverage and may use them engage a younger audience in discussions and debates that previously were the domain of recognized pundits and experts. Educators can learn from these increasingly mainstream methods of engaging young people in a dialogue and community and can use the example of social networking and online writing to find new ways of communicating with students, parents, and the wider educational community. Likewise, students have for some time had the power to publish their personal thoughts, ideas and creative videos or photographs to an appreciative audience of friends through social networking and blogging websites. Educators have an opportunity to capitalize on this enthusiasm by young people to publish more thoughtful, thoroughly developed writing that occurs when they know there is a critical audience reading their work.

\section{Description of blog assignments}

The students who completed the activities described in this essay were aged from 11 to 18 years and were enrolled in a comprehensive high school in the east of Scotland. The youngest students, aged 11 to 13 years, were in mixed ability classes while the older students were generally in ability-based high school certificate classes. Student computer access in the school was limited to one busy library lab that offered only limited availability. Teaching classrooms in the school had one internet-capable computer each that was often connected to a data projector. 


\section{A. Group journal blog}

The group journal blog grew out of the popular practice of having students keep pen-and-paper journals to reflect on their learning. The conscious-raising effect of having students reflect on the learning goals and evaluate their own progress towards meeting those goals been described by Aileen Ward (2005). In the initial iteration of this project, before the implementation of the web-based writing, students in their first year of language learning were encouraged to write a paper journal to record what they had learned to do in each set of lessons. However, the teachers leading this project reported that the task was quickly met with frustration by students who felt that the journal's audience, the teacher, already knew where their problems lay. Teachers also reported that it was difficult to find time to allow pupils to exchange journals, a process that may have allowed them to see shared areas of difficulty and to help each other problem-solve. Another challenge for students included identifying a subject for their journal entries; while some students requested assistance from the teacher in determining a good topic for their journal entries, other students were nervous about expressing their difficulties and believed they may have been the only ones with their particular problems.

In a bid to resolve these issues a group blog was begun, that is, one weblog with separate authorship rights for each student. Students could post their reflections at their convenience, when they felt they had something to say rather than for an assignment deadline. Students were able to write in the group blog and at the same time still kept their paper journals. Students could post and read each other's posts on the weblog from home, from the school library or the one classroom computer if they finished their work early. This flexibility meant that computer access both at home and in school was less of an issue than if the "task" of writing the learning blog was given as homework or as an in-class activity. Peers and teachers, including teachers from other classes, could leave comments and suggestions for improvement, advice and help or they might just say well done. For the period that this experiment was able to run there were no comments that needed to be moderated or edited and teachers reported that many students maintained their paper logs more consistently at the same time. Old and new existed in tandem at the wish of the students.

Since the completion of the first iteration of the group blog project, other Scottish educators have further developed the idea of using group blogs as a means to guide students to reflect critically on their own learning. These teachers have begun posting audio and visual work of students, including student PowerPoints, and they have made a more explicit effort to coach students on how to comment constructively. One such example in developing students' skills in constructive criticism is from The Gordon Schools, Huntly, Aberdeenshire, ${ }^{2}$ where a two stars and a wish ${ }^{3}$ approach has allowed students to both congratulate and point out areas for improvement in a constructive manner. The attitudes and expectations are not only visible on the website itself but have also been revisited on a regular basis in the face-to-face classroom. Thus, the writing and communication that is taking place online has had a noticeable effect on students' in-class performance. As a side-effect of this peer review, students are exposed to many other performances or writings and when they make comments, they adopt the role of teacher. In doing so, they read critically and when they identify an area for improvement are required to explain the very idea or point that they have themselves just been learning. This practice of explaining to one's peers serves to reinforce the lesson and encourages the student to engage in the subject manner in an active manner.

\section{B. Best Work Blog}


Students who participated in the Group Journal Blog responded positively about the experience and requested to use blogs for other purposes. Some students indicated that they wished to have a blog to publish their best work and/or final drafts of written work. Therefore, one blog was set up for an entire S2 (students aged 13 to 14 years) class where pupils were asked to post their best work from the week. Writing on the blog took place after class on the classroom computer or from students' home computers. As a result, this use of the blog did not require any additional classroom time or preparation time by the teacher. The teacher of this class reported that pupils worked harder knowing that their work would be truly public. The blog was open not only to classmates and schoolmates, but was open to the entire world - including, perhaps even more importantly, the students' parents. A second best work blog project was developed for a class of S3 (students aged 15 years). Students in this second group tended to be somewhat weaker in their language skills. They were required to create material that the teacher would post to the blog during the last five minutes of the class period. The blog was only open to the teacher, students in the class, and senior school management who were encouraged by the teacher to browse the blog and leave positive comments for the students.

Teachers reported that students who posted best work to the blogs appreciated having a wider audience than they normally would have had for traditional writing assignments. Students were able to ascertain the size of their new audience by referring to the blogs' comments and by checking the tracking statistics of the blogging software that indicates number of users who access a blog. For the blog that was open to the world, students became keenly interested in the geographical location of their readers and this interest led to the development of another project. In one primary school in the West of Scotland, the geographical statistical data was used as a launching pad for additional cultural learning activities. Students at the school chose one region or country from which a reader had come and developed an offline poster display about that region or country. The posters, in turn, were written about and photos of the displays were incorporated on the class blog site.

\section{School trip blog}

As the name implies, a school trip blog is written by students who are traveling on a school program. Traditionally, pupils on school trips have been required to write a daily diary with pen and paper and often report that the assignment seems burdensome at the time of the trip. While students usually report that they are happy to have a reminder of their trip after the event when they graduate and leave the institution, during the trip itself students have complained that writing recaps of the day's experiences does not give them a context for developing their cultural awareness. The students' comments seem to indicate that the solitary act of keeping a journal about their trip does not give them contextual support for understanding the new experiences met during their travels and suggests the students seek some kind of community or group support as they undergo the learning experience. With the support of the MFLE, two teachers developed school trip blogs. One blog was for a History and Language Trip to Auschwitz, Poland and the second blog was for a French Trip to France.

The school trip blogs were used pre-trip, during the trip, and post-trip as a way to share information and explore ideas about the travel learning experience. Before the trip, the blog was written by the teacher alone and included information to help students prepare for the trip. The teacher posted hyperlinks to sites relevant to the trip and to planning the trip and photos and student comments about previous trips. During the trip, students wrote their reflections about the trip, published photographs to accompany the written text, and even used audio recording to publish their spoken reaction to the trip. 
The blog therefore allowed students to publish written text, pictures, and spoken word reflections on their experiences.

Teachers reported that the blog daily diary was far more popular than the pen-and-paper version for three reasons. The first reason is that students were aware of the audience reading their work back home and around the world. This awareness came in the form of comments left under each post, which would be read on the trip coach or viewed by students while preparing new diary entries. In addition, teachers explained that students started to expect feedback on their writing and therefore felt obliged to write as regularly as possible and use vocabulary in their native language which was far richer than would have been used in a paper diary with a low or no audience. A final reason the online trip journal was favored includes the ability to use multimedia (text, photo, audio) that seemed to provide extra inspiration to get the students started on each post. Unlike the online journal, the pen-and-paper journal is static and does not incorporate the richness of the multimedia online journal. Teachers reported that the digital forum seemed to inspire students to engage in descriptive and personal writing that was much more vivid and fully developed than the traditional journal did. As with the Best Work Blog, the geographic location of visitors to the School Trip Blog provided material for post-trip activities. Students were asked to compare life in the country they visited not only with their own culture, but also with the cultures of countries in other parts of the world. In the case of the Auschwitz trip blog, this very activity led to a collaboration between classes in Scotland and in Georgia, USA.

\section{WebQuests Blogs}

Much in the same way that blogs have transformed more traditional kinds of writing assignments such as essay writing and journals, they have also been used in projects supported by MFLE to transform the writing portion of internet-based research activities such as WebQuests. A WebQuest is a research activity where students gather, synthesize, and analyze information from web sites that are usually chosen in advance by the teacher. Students can work together in groups or pairs on WebQuests and are given specific steps and tasks that target the learning objective defined by the teacher. In the foreign language classes supported by MFLE, WebQuests had previously been developed and required students to read web sites in the target language in order to achieve a goal, such as buying a train ticket, planning a metro journey, or booking a hotel room. Teachers give students a "challenge" to solve on the WebQuests. The challenge comes in the form of a set of questions printed out and given to the pupils. Students go to authentic web sites in the target language to find the answers or information required to solve the challenge.

Teachers with whom MFLE worked typically found that WebQuests requiring between 10 to 40 minutes of work were ideal for the students. The WebQuest provides an opportunity for independent reading and writing as students worked their way through the challenge. With the traditional pen-and-paper WebQuest report, teachers felt that the pace at which students worked greatly affected the final product of the assignments. Students who rushed and wrote too quickly did not write sufficiently in depth; on the other hand, students who wrote too slowly tended to lose interest in the WebQuest. In one experiment with WebQuest blogs, the teacher used the timed-release feature of the blog software to release the challenge questions one by one over a period of days or weeks. The challenge questions were written in advance by the teacher and set to release automatically at pre-designated intervals. Many blogging software utilities have a timed-release feature. Through the use of the timed-release of challenge questions, the WebQuest could now take place over a number of weeks, and 
more importantly, be tailored by the teacher to suit the needs of the learners.

The use of the time-released feature allowed the teacher to customize the web-based research assignment in several ways. If the students exhibited a weak point during the course of study on a particular day or week, the teacher could add websites that contained relevant grammatical or vocabulary features for that day's or week's challenge question and resources for that challenge question. By monitoring and evaluating student responses to the current challenge question, the teacher was able to adapt the assignment in a way that provided additional support to continue the next phase of the assignment. The teacher could also take into consideration the pace at which students performed on the challenge questions and modify the subsequent challenge questions if needed. Each week's challenge required 10 to 40 minutes and so did not take an excessive amount of weekly class time. Teachers wrote the challenges to end in a "cliff-hanger" each week that would keep the students guessing and, hopefully, thinking about the challenge until the next one. Students were able to comment on the challenge question and write their guess about what they thought they would be asked to do in the next challenge. This element of suspense heightened interest and the answers often gave the teacher an indication of the kind of task that would be well-received by students the subsequent week. Teachers reported that they did not feel the preparation time to create the challenge or monitor the blog was excessive. Most reported that they did not need more than ten minutes a week to develop the challenge and post it to the blog for each of the teacher's classes doing that assignment.

\section{Challenges, lessons learned, and issues to keep in mind}

\section{A. Audience, motivation, and voice}

One of the most easily identifiable benefits of using a blog in a writing assignment is the possibility of widening the readership for students' writing. This potential feature in turn relates to the narrative voice used by writers and also can have an impact on students' motivation to continue writing. However, simply publishing students' writings on the internet with a blog does not necessarily guarantee a wide or committed audience. It does not take a great deal of effort to search the internet for blogs that have extremely limited readership. However, in education where entire classes are publicly sharing their views on a common subject, the audience is at least the size of the class and may also include parents, other family members, and the wider school community. Inviting parents and others within the school community to interact with the blog is one means of raising readership fairly easily. For example, the first school trip blog supported by the MFLE logged more than 7500 visits in just six days.

In the examples of the blogs that are described earlier in this paper, the teachers and students reported that they considered the learning activity a success. The blogs solved the problem of students who did not feel motivated to write a traditional pen-and-paper essay assignment by providing the incentive of writing for a wider audience. In addition, the blog assignments provided a way to share writing outside of class time, thus giving students more flexibility in developing thoughtful responses, more time to think about developing their written responses, and allowing teachers to use class time for other learning activities. Teachers who developed blog activities that were open to a worldwide audience reported that they had to spend time developing and nurturing the larger audience for their students. In a non-education setting, the blog audience typically grows by word-of-mouth and therefore much more slowly than is practical for a term-limited project. MFLE provided guidance to these teachers for growing and sustaining an audience for their students' blogs. In all cases, the teachers were required to be 
proactive and some of the methods used included finding partner schools, enlisting parents, and recruiting colleagues at other institutions and other classes within the school to respond to the blogs.

Teachers reported that once an audience had been identified and introduced to the blog, they continued to find it necessary to provide very clear guidance to students for how to write to keep the audience engaged. For example, one teacher in the area of Modern Studies reported that her blog project met only limited success because of issues with developing and retaining an audience. In this project, four senior students were required to undertake a major research project based on comparisons between the UK and the US. The research project necessitated carrying out primary research, including conducting interviews with Britons and Americans to gather information about the public's view of the health care system. A street questionnaire was used to gather the views of the British citizens, but the four senior students needed to find a more convenient way to gather opinions of the US citizens. The students decided to implement a group blog administered by the four students to gather data from the US citizens. The strict timeline imposed by the academic calendar posed a significant challenge to building an audience that could provide sufficient data for the students. The Scottish students' teachers helped to remedy this situation by identifying and contacting a US teacher who located former students of voting age to respond to the blog. Teachers reported that the Scottish students' motivation for the research project was strengthened by the increased activity on their blog. However, the teachers also observed that the motivation of the US respondents seem to decline over the term of the project. The teachers determined that the tone and type of responses provided by Scottish students to the US respondents dampened the enthusiasm of the US respondents for the project. The teachers remarked that Scottish students tended to keep their responses to the US respondents' comments curt. When US respondents provided information on the blog they did not receive acknowledgement beyond a short Thank you statement. Therefore, the posts were made with decreasing frequency and the audience began to wane. Teachers remarked that the formal, impersonal voice used by the Scottish students might also have been found uninviting to the US respondents.

Teachers involved in this somewhat failed blog activity believed the failure could be partly attributed to the US respondents' lack of interest in the subject and also to the difficulty the Scottish students had engaging their audience in the discussion. The teachers clearly felt that future blog projects would benefit by attending to students' skills in cultivating and sustaining audience interest. The use of appropriate voice and tone, tips for responding effectively to the audience comments, and methods for communicating more clearly in the author's or authors' blog posts would be helpful topics to include in directions for future blog projects. Teachers also remarked that the blog assignment provided an opportunity to discuss voice in writing. Students were instructed to think about precisely who constituted their audience and to think about how to write in a voice that was appropriate for the subject and the audience. Drawing students' attention to the different perspectives that their potential audience might hold helped them understand that different registers in tone and different vocabulary and terms could be interpreted differently by different reader groups. This awareness helped students expand their writing style and vocabulary in ways that they might not have had they been writing solely for the teacher. For less advanced classes the personal nature of writing a blog lends itself well to the personal writing they are expected to produce in the course of their 5-14, Standard Grade or National Qualifications study. Teachers also reported that by making students aware of the wider audience and the importance of writing style and persona, students were encouraged to use more sophisticated style and structures and to develop more fully their ideas. For example, in a short period of writing on the 
blog, a mixed ability S3 class increased its use of more complex structures to express and justify their opinion using phrases such as je pense que.... and à mon avis... in place of previously popular simple structures such as parce que c'est cool.

As previously mentioned in this article another benefit of the blog was that the exercise of writing for a wider audience seemed to motivate the students. In the blog projects supported by the MFLE, the statistics for the France Trip travel blog seem to indicate high student motivation. In that blog project, students wrote about their experiences on a travel and study trip to France and posted their writings during the trip. Over the course of seven days 400 comments were left for the students which clearly indicated strong parental and peer interest in the activities the students described during their trip. Many of the comments responded to questions that the students had set out to answer through interviewing locals or through journal writing at the end of each day. Teachers working on the project reported that student motivation to carry out and complete required assignments such as writing the blog and creating audio reports was quite high. The students on the France Trip seemed particularly keen to work on the audio reports and were eager to speak French for the 8000 subscribers to their podcast radio show. Teachers remarked that the students did not always express the same enthusiasm to speak French in public in the classroom atmosphere. The MFLE recommended to the teachers to include a blogroll, or links to other related blogs on the main page of the blog, in future travel blogs in order to attract a larger audience that already reads blogs and listens to podcasts on similar topics. The use of a blogroll is one means of developing the audience for a blog.

\section{B. Privacy and child protection}

The students in classes where these MFLE blog and podcast learning activities have been developed are in the K-12 age group, and therefore great care has to be taken to protect their identity. In accordance with national guidance on the matter, East Lothian Council, a school district to the East of Edinburgh, Scotland, created a webpage anyone in the community could edit, or a "wiki", and set out the basic outline of a potential policy for self-publishing on the web by young students. After two weeks of open invitation to the community, edits and expansions of this text were made by parents, teachers, students, school managers, Education Authority leaders, and outside experts. The result is a comprehensive and positively-worded strategy and policy to encourage self-publishing of student work on the web, whether that be in written, photographic, audio or video form, while keeping children safe. A simplified version has been adapted to help explain its contents to younger children involved in self-publishing using blogs or audio podcasts. The main tenet of the policy is that children must not be identifiable by association. This tenet requires that students' first names must never be published with their last names and their photographs can never published with any name. In addition to maintaining child protection for young self-publishers in the Scottish system, the policy has also provided teachers with the confidence to develop young people's digital literacy skills further. The policy can be viewed, edited, copied and adapted for other schools. ${ }^{5}$

\section{Summary of benefits in using the blogs}

As the examples in this article demonstrate, language teachers who have been supported by the MFLE have been able to use blogs to give students the opportunities to write for a real audience and to read culturally authentic material in a guided and structured learning activity. The examples in this article can serve as models for how blogs can be used to increase the opportunity for peer feedback and 
to extend the writing activity beyond the class room, thus helping to achieve the goals of the third millennial classroom. The goals of the third millennial classroom include increasing collaboration, inclusiveness, flexibility, and relevance in the learning experience (Felix, 2005). Teachers in the projects described in this article indicated that blogs encouraged their students to write because of their question-and-response format. Having students ask the critical questions rather than having the teacher alone asking questions increases the opportunity for students to develop meta-cognition and to construct knowledge in an active manner.

Over the course of the terms during which the blogs were used, researchers from the MFLE who worked with and supported the teachers using the blogs began to recognize another benefit of the writing activity. In addition to the benefits to language and culture study, the blogs also offered the possibility to encourage students to think more generally about their learning. The MFLE researchers recognized that the principles outlined in the Assessment is for Learning project could be met with the blog. One of the practices in assessing learning described in the Assessment is for Learning project requires that students keep a learning log that summarizes what they achieve in each lesson. In the past learning logs were kept on paper but teachers and students commented that it was often inconvenient to share the logs for peer assessments. Using the paper logs was seen as cumbersome and awkward and limited peer assessment because only one copy of each log could be swapped at a time. By the end of the term where MFLE worked with teachers to use blogs, senior students were asked to write their learning logs as learning blogs. The students were able to design their blog and to link to the blogs of their peers. Students commented on each other's learning blog and left motivational messages for each other. The classroom teacher and other teachers invited onto the projects from abroad also leave constructive comments on student posts. The MFLE will advise teachers of the possibility of using the learning blog to provide recommended links to students. The advantages of publishing a learning log have been discussed by Dörnyei (2005). For example, he describes an experiment where the publication of students' learning logs increased the motivation of students when they saw that their peers had experience similar highs and lows during their course of study.

\section{Future directions for blog writing projects in foreign language}

Researchers at the MFLE believe that there are many possibilities for designing blog writing activities that have not yet been put into practice in the foreign language classroom. These researchers are guided by the principles described in the Assessment is for Learning project that emphasize the importance of collaborative learning and peer assessment and the importance of helping students tailor their writing voice and style according to their audience. They have developed two main goals that are achievable with existing classroom technology and that seem to be the logical next steps for blogging in foreign language education. Those goals include having students engage more in creative writing and enabling students to use their own hand-held technologies.

\section{A. Creative writing}

Creative writing is one way for even very young or very beginning language students to engage in writing in the foreign language. One example of a possible creative writing project using a blog could be a fairy tale assignment. Over the course of a six-week period, the fairy-tale project would have students read fairy tales, fables or short stories, and then have students write their own fairy tales either individually but with peer commenting or as a group project. In this kind of writing assignment, the blog 
would replace the word processor and the only technology required would be a computer with internet access to a blog web site. Discussion, peer support and brainstorming would be used in a face-to-face small group setting within the classroom. Since discussions are typically limited in any class due to time constraints, the students may not have adequate think to think and imagine their tale. In this context, the blog would allow students to share and develop their collaborative creative ideas via the online writing. Students would be able to keep track and record all their ideas and can even suggest possible next steps to the stories or poems being created by their classmates by using the comments feature of the blog. While some of the writing on the blog in this type of creative writing assignment would have to be done in class, the students could be assigned as part of a homework or library reading task to read the contributions of others. The contributions might be entirely in the target language or could also be a mixture of mother tongue and foreign language (franglais, spanglish...). In addition to the opportunity to write and collaborate on a creative project, this kind of assignment also allows teachers to share links to relevant authentic websites that might include fairy tales, poetry, or folklore in the target language. This kind of thoughtful interaction enables students, even young students, to explore more deeply a subject area than is normally possible within the constraints of the 45-minute lesson.

\section{B. Harnessing pupils' own technology}

Increasingly students have their own communication devices such as mobile phones, personal digital assistants, and other hand-hand technologies at their disposal. Students commonly use these devices in their daily lives to communicate and to access and share information and so it seems logical to use these devices in education. One possible way to incorporate students' own technologies into a blogging activity is to allow students to use their mobile phone to publish text, video, and audio to the blog. The process of publishing content to a blog using a mobile phone is called "moblogging." The MFLE supported small scale pilot projects where students' own technologies were used. Teachers who led moblogging activities reported that the pupils found the process of publishing to the site with their mobile phone quite simple. The project required that the teachers upload the students' telephone numbers into the blogging service before students were able to publish. Teachers reported that student motivation to write short notes in the target language was very high in the pilot projects. Some students used the full range of services provided by their mobile phones and made short audio recordings with their phones as they travelled that they later published on the blog. One of the obvious ways that moblogging differs from blogging is that moblogging can be done from any place where the user has access to his or her phone service. The ability to write and post audio and video to a blog from anywhere opens up possibilities for language-related activities. Blog assignments can be done quickly and conveniently and do not have to be bound to a computer with internet access. Teachers considering using a moblog in a foreign language activity could consider different ways to take advantage of the fact that their students can publish on the blog while fully mobile and outside of the classroom walls. Elements to keep in mind include potential costs to students for making calls from their mobile phone. When using the personal technologies owned by students, it would be a wise idea to develop a parental permission form before undertaking the project. It would also be wise to offer students alternatives for posting to a class blog so that those without access would still be able to participate in the activity.

\section{Conclusion}

It is the spontaneity of one-click publishing, the empowerment of pupil and teacher to post and to 
comment, the sense of real worldwide audience and the ability to collaborate beyond the barrier of the classroom that makes writing and reading through blogs a very educationally-interesting proposal. Furthermore, as students' home technology continues to increase in sophistication and sometimes evens rivals what is found in schools, using blogs makes sense for two reasons. The first reason is that writing a blog can be done with simple hardware. A second reason is that students are increasingly comfortable writing and communicating online through blogs and other social networking sites. Having the guidance of a teacher and the positive involvement in a learning activity will help the students develop more sophisticated skills for communicating in the twenty-first century. Students may learn the lesson of ownership and responsibility for their recreational blog writing through their experience of having it published and criticized constructively by those in the classroom and, more importantly, those outside the classroom in the wider world. Through the use of blogs, the teacher will have an additional tool in his or her toolbox for teaching writing and reading skills. And, above all, the entire educational community has an exciting opportunity through blogs to motivate large numbers by using technology that is available and which increasingly forms part of teenagers' lives. As blogging and online writing become a more mainstream medium for writing and self-expression, the educational community needs to adapt and be prepared to teach students how to use these important tools. If educators do not guide students in the development of sound online writing practice, then it is possible we will have a generation of highly competent monolingual technicians with nothing much to say.

\section{Notes}

1. Birch, Paul, Founder of Bebo.com in Mediasnackers 15 January 2007.

2. http://thegordonschools.typepad.co.uk/ratemymates/

3. http://tinyurl.com/2vr96r

4. Interactive Chatting Teddies wall chart of visits by country: http://tinyurl.com/2zwp7z

5. http://edubuzz.org/support

\section{References}

Dörnyei, Z. (Speaker). (2005). A closer look at Motivation in the language learning classroom [Motion picture]. Stirling: Scottish Centre for Information on Language Teaching and Research (Professional Services), University of Stirling. DVD and online video. Retrieved September 18, 2007, from http://www.scilt.stir.ac.uk/dvd/index.html.

Felix, U. (2005). E-learning Pedagogy in the Third Millennium: The need for combining social and cognitive constructivist approaches. ReCALL 17(1): 85-100.

McIntosh, E. (2005). The 3rd Millennial Linguist: Developing New Pedagogies in Scottish Languages. Scottish Languages Review 12. Retrieved September 18, 2007, from http://www.scilt.stir.ac.uk/ SLR/Current\%20Issue/SLR12\%20E McIntosh.pdf.

Ward, A. (2005). How do they and we know they're learning? Scottish Languages Review 10. Retrieved September 18, 2007, from http://www.scilt.stir.ac.uk/SLR/Issue10/AileenWard.htm. 